Research Article

\title{
Pattern of antibiotic use in neonatal intensive care unit in tertiary care hospital in Southern India
}

\author{
Anjali Ravindra Shinde ${ }^{1}$, Jaydeep M. Bairagi ${ }^{2}$, Chitra C. Khanwelkar ${ }^{3}$, \\ Ravindra Vasantrao Shinde ${ }^{4}$, Rajsinh Vishwasrao Mohite ${ }^{5 *}$
}

\begin{abstract}
${ }^{1}$ Department of Pharmacology, Prakash Institute of Medical Sciences Urun-Islampur, Mahatashtra, India

${ }^{2}$ Drug Safety Physician, Cognizant Technology Solutions Pune, Maharashtra, India ${ }^{3}$ Department of Pharmacology, ${ }^{4}$ Department of Microbiology, ${ }^{5}$ Department of Community Medicine, Krishna Institute of Medical Sciences, Karad, Maharashtra, India
\end{abstract}

Received: 01 June 2016 Accepted: 01 July 2016

*Correspondence to: Dr. Rajsinh Vishwasrao Mohite, Email: rajsinhmohite124@ gmail.com

Copyright: (C) the author(s), publisher and licensee Medip Academy. This is an openaccess article distributed under the terms of the Creative Commons Attribution NonCommercial License, which permits unrestricted noncommercial use, distribution, and reproduction in any medium, provided the original work is properly cited.

\begin{abstract}
Background: Repeated and prolonged courses of antibiotics exposure have resulted in an increase in the prevalence of hospital acquired infections and antibiotic resistant profile. The objective of this study was to quantify the use of antibiotics in a neonatal intensive care unit (NICU) from rural tertiary health care centre.

Methods: A hospital based cross-sectional study was conducted in the NICU of tertiary care hospital located in western Maharashtra, India during the year 2011-12. A total of 237 neonates admitted to NICU from October 2011 to March 2012 were enrolled in the study according to inclusion criteria of the study. Demographic details, data on antibiotic prescriptions (name, dose, frequency, route of administration) were recorded by utilizing pre-tested structured proforma.

Results: A total of 3822 prescriptions were received by the neonates and commonly prescribed antibiotics were amikacin $(75.53 \%)$, cefotaxime $(43.34 \%)$ and ampicillin $(31.33 \%)$ respectively. It was also noted that $50 \%$ of the drugs prescribed were in compliance with the national list of essential medicines 2011. The $\max , 68.75 \%$ of antibiotics prescribed were in generics forms however, $12.5 \%$ were prescribed in the form of fixed dose combinations.

Conclusions: The revealed that $3^{\text {rd }}$ generation cephalosporins and amikacin are most commonly used antibiotics in NICU.
\end{abstract}

Keywords: NICU, Preterm, Drug utilization, Drug prescriptions

\section{INTRODUCTION}

Neonates are most prone for infections due to low immunity. Drugs used for treatment of neonates are showing rapid advancements in recent years. Since last half century there is increase in average number of drugs used per neonate in neonatal intensive care unit (NICU). ${ }^{1-}$

${ }^{3}$ Neonates are exposed to high numbers of drugs, putting them at higher risk of adverse drug reactions. Trends in prescription pattern for drugs in NICU are changing drastically but current data on drug utilization patterns in NICU is very limited. ${ }^{4}$ Few published studies are available on drug utilization in neonates in India as well as in United States of America and Europe and considering this World Health Organization(WHO) aim to promote research in the pediatric population. ${ }^{5-7}$ 
Neonates, mainly premature are at high risk of bacterial infections than term neonates as their physiological functions are immature lead to high morbidity and mortality. Therefore clinicians start using antibiotics empirically or most of the times prophylactically. In some cases with the advent of knowledge of culture sensitivity, clinicians either stop or change the antibiotics. But in most of the cases either they do not perform culture and sensitivity or they continue the antibiotics for long period of time though the organisms are not sensitive could be due to lack of knowledge or facilities.

Repeated and prolonged courses of antibiotics exposure have resulted in an increase in the prevalence of hospital acquired, antibiotic resistant organisms such as methicillin resistant staphylococcus aureus, vancomycin resistant Enterococcus etc. Evaluation of antibiotic use is therefore prime important since the prevalence of hospital acquired antibiotic resistance in organisms is increasing in neonates. ${ }^{8,9}$ The present study aimed to quantify antibiotic use in a neonatal intensive care unit of tertiary care hospital situated in rural part of western Maharashtra, India and the data generated from this could be used to develop effective drug policy as well as prioritization in future research.

\section{METHODS}

A hospital based cross sectional study was conducted in rural tertiary health care centre located in western Maharashtra, India. The study was conducted in the year $1^{\text {st }}$ October 2011 to $31^{\text {st }}$ March 2012 after obtained institutional ethical approval. The study enrolled all neonates admitted and treated in NICU during the period of October 2011 to March 2012. A total of 249 neonates were admitted during study period, of which 237 were enrolled according to exclusion criteria of present study as a time bound sample size.

\section{Exclusion criteria}

Neonates who were discharged or transferred to other ward or hospital or died within 2 days of NICU stay are excluded from the study. Neonates suffering from cancer, diagnosed with surgical problem, post-operative neonates admitted in NICU, neonates receiving phototherapy for neonatal jaundice and neonates on oxygen therapy are also not taken in the study.

\section{Data collection}

The data were collected by principal investigator utilizing pre-tested structured proforma that include neonates demographic data i.e. date of birth, weight at birth, gestational age in weeks, gender, diagnosis, outcome etc. as well as data pertained to antibiotic prescriptions like name, dose, frequency, route of administration etc. were recorded in NICU from the day of admission till outcome as discharge or death. Neonates were classified into five different groups according to age of gestation in weeks at the time of birth. Once neonates have been discharged or transferred to other ward or hospital, no further data was collected. We did not get any data regarding drugs given to the mother. The data so collected were entered into MS Excel, analysed and distributed into frequency percentage in tabular and graphical form.

\section{Ethical consideration}

After obtaining permission from the institutional ethics committee (IEC) the study was carried out in the NICU of the tertiary care hospital in Southern India.

\section{RESULTS}

The study spanning over six month period enrolled 237 neonates were classified in five different groups according to weeks of gestation.

Table 1: Characteristics of the neonates $(n=237)$.

\begin{tabular}{|llllll|}
\hline Weeks of gestation & $\begin{array}{l}\mathbf{2 4 - 2 7} \\
\text { (Very early pre- } \\
\text { term neonates) }\end{array}$ & $\begin{array}{l}\mathbf{2 8 - 3 0} \\
\text { (Early pre-term } \\
\text { neonates) }\end{array}$ & $\begin{array}{l}\mathbf{3 1 - 3 3} \\
\text { (Mid pre-term } \\
\text { neonates) }\end{array}$ & $\begin{array}{l}\mathbf{3 4 - 3 6} \\
\text { (Late pre-term } \\
\text { neonates) }\end{array}$ & $\begin{array}{l}\mathbf{3 7} \\
\text { (Term } \\
\text { neonates) }\end{array}$ \\
\hline Demographic distribution (M/F) & $4 / 1$ & $16 / 9$ & $23 / 21$ & $34 / 13$ & $85 / 31$ \\
\hline Total birth weight $(\mathrm{kg})$ & 6.8 & 33.86 & 72.596 & 84.63 & 285.01 \\
\hline Mean birth weight $(\mathrm{kg}) \pm \mathrm{SD}$ & $1.36 \pm 0.31$ & $1.35 \pm 0.2407$ & $1.649 \pm 0.4116$ & $1.800 \pm 0.4268$ & $2.457 \pm 0.6315$ \\
\hline Length of hospital stay (days) & 49 & 270 & 387 & 462 & 667 \\
\hline Length of hospital stay (mean \pm SD) & $9.8 \pm 6.30$ & $10 \pm 8.54$ & $9.439 \pm 5.96$ & $8.864 \pm 6.74$ & $6.119 \pm 4.53$ \\
\hline No. of prescriptions & 98 & 508 & 906 & 864 & 1446 \\
\hline
\end{tabular}

As shown in Table 1 , of the 237 neonates studied the proportions of pre-term and term neonates were $51.05 \%$ and $48.94 \%$ respectively. The proportion of male neonates $(68.35 \%)$ was higher than females $(31.64 \%)$. Mean birth wt. for full term neonates was 2.457 ( $\mathrm{SD} \pm 0.6315)$, and for very early pre-term neonates was $1.36(\mathrm{SD} \pm 0.3073)$ and for other groups was in-between. Mean length of hospital stay was higher, $9.8(\mathrm{SD} \pm 8.535)$ days for the neonates in 
group 28-30 weeks of gestation than term neonates, 6.1 (SD \pm 4.53 ) days. A total of 2376 prescriptions were scrutinized for preterm neonates whereas 1446 were for full term neonates.

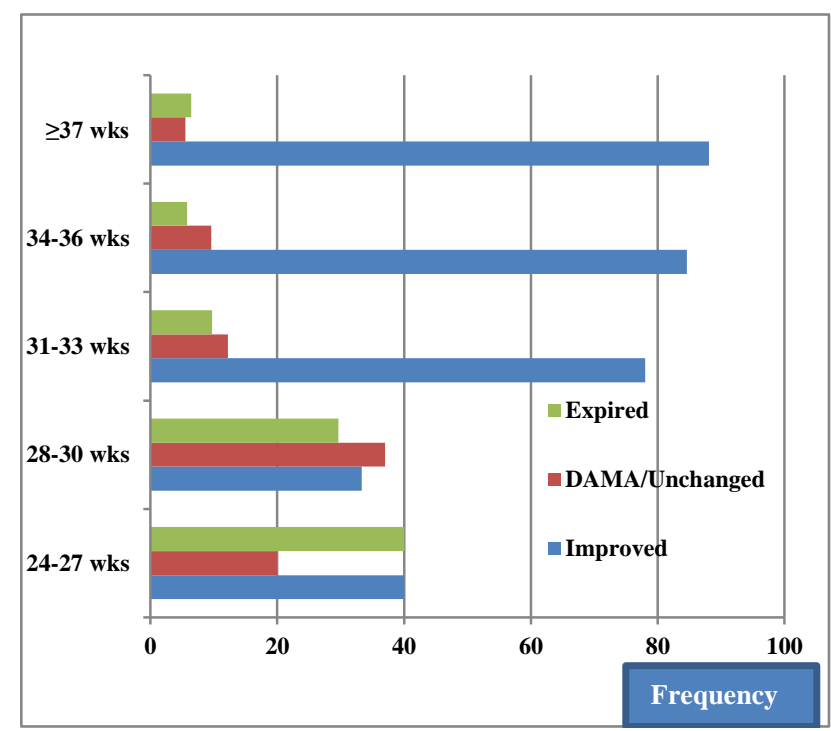

Figure 1: Condition of neonates at the time of discharge.

According to the data available on condition of patients at the time of discharge, we divided them into expired, improved and discharge against medical advice (DAMA) discharge or with unchanged status at discharge. $93.75 \%$ improvement was seen in neonates from the group of $\geq 37$ weeks of gestation whereas $36 \%$ improvement was seen in neonates from the group of 28-30 weeks of gestation. Mortality was highest in 24-27 weeks group (40\%) followed by $28-30$ weeks of gestation (32\%) group. A total of 24 neonates $(10 \%)$ of the study population died during their stay in the hospital (Figure 1).

Table 2: Exposure rates (\%) of most often prescribed drugs for neonates in 24-27 weeks of gestation.

\begin{tabular}{|lccc|}
\hline \multicolumn{4}{|c|}{ Drug for week of gestation: } \\
& Number & Incidence & Antibiotic days \\
\hline Cefotaxime & 3 & 60 & 24 \\
\hline Amikacin & 3 & 60 & 24 \\
\hline $\begin{array}{l}\text { Cefoperazone } \\
\text { +sulbactum }\end{array}$ & 3 & 60 & 6 \\
\hline Metronidazole & 3 & 60 & 4 \\
\hline Vancomycin & 3 & 60 & 3 \\
\hline Ceftazidime & 1 & 20 & 3 \\
\hline Ofloxacin & 1 & 20 & 9 \\
\hline $\begin{array}{l}\text { Tobramycin } \\
\text { eye drops }\end{array}$ & 1 & 20 & 1 \\
\hline
\end{tabular}

Neonates got admission in NICU for preterm care, septicemia, meconium aspiration syndrome, birth asphyxia etc. We observed that $98 \%$ of our study patients (neonates) received antibiotics. Pattern of use of single, double and multiple antibiotics was received by $16 \%$, $55 \%$ and $29 \%$ neonates respectively. However, four patients did not receive any antibiotic. It was noted that $50 \%$ of the antibiotics prescribed were in compliance with the national list of essential medicines 2011. The percentage of prescriptions of generic antibiotics was $68.75 \%$ whereas, $12.5 \%$ of antibiotics were prescribed in the form of fixed dose combinations (sulfamethoxazole + trimethoprim, cefoperazone + sulbactum).

Table 3: Exposure rates (\%) of most often prescribed drugs for neonates in 28-30 weeks of gestation.

\begin{tabular}{|c|c|c|c|}
\hline \multicolumn{4}{|c|}{ Drugs for weeks of gestation: $28-30(n=25)$} \\
\hline & Number & Incidence \% & Antibiotic days \\
\hline Amikacin & 18 & 66.66 & 109 \\
\hline Cefotaxime & 12 & 44.44 & 84 \\
\hline Ampicillin & 6 & 22.22 & 23 \\
\hline Vancomycin & 5 & 18.51 & 24 \\
\hline $\begin{array}{l}\text { Cefoperazone } \\
\text { +sulbactum }\end{array}$ & 5 & 18.51 & 13 \\
\hline Ofloxacillin & 4 & 14.81 & 27 \\
\hline Meropenam & 3 & 11.11 & 29 \\
\hline Ceftazidime & 3 & 11.11 & 18 \\
\hline Metronidazole & 3 & 11.11 & 10 \\
\hline Clavum & 1 & 3.7 & 4 \\
\hline Ceftriaxone & 1 & 3.7 & 4 \\
\hline Linezolid & 1 & 3.7 & 2 \\
\hline $\begin{array}{l}\text { Tobramycin } \\
\text { eye drops }\end{array}$ & 1 & 3.7 & 2 \\
\hline
\end{tabular}

Table 4: Exposure rates (\%) of most often prescribed drugs for neonates in 31-33 weeks of gestation.

\begin{tabular}{|lccc|}
\hline \multicolumn{4}{|c}{ Weeks of gestation: 31-33 } \\
\hline & Number & Incidence & Antibiotic days \\
\hline Amikacin & 27 & 64.28 & 146 \\
\hline Ampicillin & 16 & 38.09 & 71 \\
\hline Cefotaxime & 16 & 38.09 & 86 \\
\hline $\begin{array}{l}\text { Cefoperazone } \\
\text { +sulbactum }\end{array}$ & 14 & 33.33 & 80 \\
\hline Metronidazole & 10 & 23.80 & 40 \\
\hline Vancomycin & 7 & 16.66 & 48 \\
\hline Ceftazidime & 4 & 9.52 & 20 \\
\hline Meropenam & 3 & 7.14 & 37 \\
\hline $\begin{array}{l}\text { Tobramycin } \\
\text { eye drops }\end{array}$ & 3 & 7.14 & 4 \\
\hline Ceftriaxone & 2 & 4.76 & 8 \\
\hline $\begin{array}{l}\text { Ofloxacin } \\
\text { Syrup }\end{array}$ & 2 & 4.76 & 10 \\
\hline $\begin{array}{l}\text { cotrimoxazole } \\
\text { Mupirocin } \\
\text { ointment }\end{array}$ & 1 & 2.38 & 5 \\
\hline
\end{tabular}

Table 2, 3, 4, 5 and 6 depicts the exposure rates of antibiotics prescribed according to different gestational age groups. Age group 24-27 weeks of gestation showed higher incidence of prescribing with cefotaxime followed 
by amikacin and cefoperazone. Third generation cephalosporins were more commonly prescribed for this group. $20 \%$ patients received prescription of ofloxacin, tobramycin eye drops also (Table 2). Age group of 28-30 weeks of gestation showed most commonly prescribed antibiotics was amikacin followed by cefotaxime (Table 3). Similar findings have also been observed in age group 31-33wks of gestation and 34-36 weeks of gestation (Table 4 and 5). The term neonatal age group, $\geq 37$ weeks of gestation showed higher incidence of prescribing of amikacin, cefotaxime followed by ampicillin. Fewer incidences are seen with crystalline penicillin, gatifloxacin, and linezolid (Table 6).

Table 5: Exposure rates (\%) of most often prescribed drugs for neonates in 34-36 weeks of gestation.

\begin{tabular}{|lccc|}
\hline \multicolumn{4}{|c|}{ Weeks of gestation: 34-36 $(\mathbf{n = 4 7})$} \\
\hline Number & Incidence\% & Antibiotic days \\
\hline Amikacin & 40 & 78.43 & 234 \\
\hline Cefotaxime & 20 & 39.21 & 108 \\
\hline Ampicillin & 19 & 37.25 & 98 \\
\hline Vancomycin & 9 & 17.64 & 59 \\
\hline Metronidazole & 9 & 17.64 & 42 \\
\hline $\begin{array}{l}\text { Cefoperazone } \\
\text { +sulbactum }\end{array}$ & 7 & 13.72 & 43 \\
\hline Ceftriaxone & 4 & 7.84 & 49 \\
\hline Ceftazidime & 2 & 3.92 & 7 \\
\hline Ofloxacin & 1 & 1.96 & 2 \\
\hline $\begin{array}{l}\text { Tobramycin } \\
\text { eye drops }\end{array}$ & 1 & 1.96 & 4 \\
\hline
\end{tabular}

Table 6: Exposure rates (\%) of most often prescribed drugs for patients in $\geq 37 \mathrm{wks}$ of gestation.

Drugs for weeks of gestation: $\geq 37$ weeks ( $n=116)$

\begin{tabular}{|lccc|}
\hline & Number & Incidence $\%$ & Antibiotic days \\
\hline Amikacin & 88 & 80.73 & 416 \\
\hline Cefotaxime & 50 & 45.87 & 221 \\
\hline Ampicillin & 32 & 29.35 & 139 \\
\hline $\begin{array}{l}\text { Cefoperazone } \\
\text { tsulbactum }\end{array}$ & 22 & 20.18 & 93 \\
\hline Metronidazole & 14 & 12.84 & 60 \\
\hline Vancomycin & 10 & 9.17 & 55 \\
\hline Ceftriaxone & 8 & 7.33 & 42 \\
\hline Ceftazidime & 8 & 7.33 & 32 \\
\hline $\begin{array}{l}\text { Tobramycin } \\
\text { eye drops }\end{array}$ & 3 & 2.75 & 1 \\
\hline Ofloxacin & 2 & 1.83 & 9 \\
\hline $\begin{array}{l}\text { Gentamicin } \\
\text { Meropenam }\end{array}$ & 2 & 1.83 & 6 \\
\hline Linezolid & 1 & 1.83 & 10 \\
\hline $\begin{array}{l}\text { Gatifloxacin } \\
\text { eye drops }\end{array}$ & 1 & 0.91 & 1 \\
\hline $\begin{array}{l}\text { Crystalline } \\
\text { penicillin }\end{array}$ & 1 & 0.91 & 1 \\
\hline
\end{tabular}

\section{DISCUSSION}

The present study described the prescription profile of antibiotics in neonatal intensive care unit of a tertiary care hospital from rural establishment of western Maharashtra state. The study revealed that cefotaxime and amikacin to be most commonly used antibiotics followed by ampicillin in NICU. The Studies done in UK and Australia, reports that Gentamicin to be the most frequently used antibiotic. ${ }^{10}$ A study conducted in Italy, reports amikacin and ampicillin to be most commonly used antibiotic in NICU11 whereas a study conducted by Clark RH from USA reports, cefotaxime as commonly used antibiotics in NICU. ${ }^{2}$

Third generation cephalosporins like cefotaxime, ceftriaxone, ceftazidime, cefoperazone are prescribed more commonly in all five groups of neonates in our study. Approximately 56\% low birth weight neonates (Weight $\leq 1.5 \mathrm{~kg}$ ) received third generation cephalosporins with $39 \%$ mortality in them. Neonates received these antibiotics in first three days of life. Previous studies report that use of third generation cephalosporins increases the risk of invasive candidiasis and death with risk increased in low birth weight neonates (weight $\leq 1.5 \mathrm{~kg}$ )..$^{2,12,13}$ In vitro susceptibility data suggest that third-generation cephalosporins are not more effective in treating sepsis than the currently recommended antibiotics viz. benzyl penicillin and gentamicin. ${ }^{14}$ Gentamicin-based regimens should be used in preference to cefotaxime-based treatments, because of lower levels of susceptibility to cefotaxime and the need to avoid exerting selective pressure for resistance. ${ }^{15}$

Second most commonly used antibiotic in this study was amikacin and $75 \%$ of preterm neonates were receiving amikacin. Dose of amikacin should be once every 36 hours in babies less than 32 weeks of gestation and for all other babies dose is once every 24 hours. ${ }^{16}$ It is a drug with very narrow therapeutic range and can cause side effects, such as nephrotoxicity and ototoxicity if 'trough blood level' in excess go uncorrected. Neonates are a high-risk population for hearing loss, and when ototoxicity occurs, it places a burden of disability on the affected individual. ${ }^{17}$ Therefore trough serum level should be checked before the fourth dose and dose interval should be increased if level is more than $8 \mathrm{mg} / \mathrm{l}$. The toxicity is increased if amikacin is prescribed for more than 10 days and when two or more aminoglycosides are prescribed together. ${ }^{16}$ In our study, dose interval for amikacin was 12 hours for all neonates. $6.25 \%$ (11) neonates received amikacin for more than 10 days and 2 neonates received two aminoglycosides antibiotics. We did not get any mention about monitoring of trough levels during the treatment with amikacin in our study.

Vancomycin should be reserved for episodes of staphylococcal infection confirmed to be resistant to flucloxacillin or gentamicin and monitoring of plasma level is necessary if it is to be given in first week of life. ${ }^{18}$ 
In our study, vancomycin usage was not guided by culture sensitivity testing and we do not get any mention of plasma level monitoring.

There is too little published experience for the manufacturers to have yet recommended the use of meropenam in children less than 3 months old. ${ }^{19}$ There is little published information on neonatal use of Linezolid and almost none on uses in preterm babies and manufacturers do not recommend use of Linezolid in children under 18 years of age. ${ }^{20}$ In our study, incidence of usage of meropenam was $3.43 \%$ and $0.85 \%$ for linezolid.

According to summary of product characteristics (SPC) of tobramycin and gatifloxacin eye drops, these drugs should be used in children of one year and above. ${ }^{21,22}$ Their usage in neonates is not mentioned in neonatal formulary-6 (NF6). Ofloxacin is contra-indicated in children or growing adolescents, and in pregnant or breast-feeding women, as there is risk of damage to the cartilage of joints in the growing subjects. ${ }^{23}$ In our study ofloxacin was given to only 10 neonates. The use of fixed dose combination, sulfamethoxazole and trimethoprim (SEPTRAN) in neonates is not mentioned in NF-6. ${ }^{24}$ In our study we found that $98 \%$ neonates received antibiotics with culture sensitivity testing done only in few neonates. Out of which $84 \%$ neonates received two or more than two antibiotics increasing the chances of drug interactions and cost of treatment. Therefore average number of antibiotics used per neonate should be kept limited to reduce the risk of drug interactions. Intense monitoring of each neonate for adverse drug reactions should be focused. Use of drugs whose safety has not been established in neonates should be curtailed.

Guidelines should be developed for empiric use of antibiotics in neonates according to microbial profile prevalent in the area which further combat the development of antibiotic resistance and minimize the cost of treatment. Further similar studies should be conducted in periods of time to know the trend of antibiotics usage and change in sensitivity pattern of bacteria in NICU.

\section{Recommendations}

- Monitoring of plasma level should be done with amikacin and vancomycin in neonates to minimize the risk of ototoxicity and nephrotoxicity

- Narrow spectrum antibiotics should be used to minimize the risk of bacterial resistance and fungal infections

- Use of antibiotics should be guided by culture sensitivity testing

- Use of drugs whose safety has not been established in neonates should be curtailed

- Empirical and Prophylactic usage of antibiotics for prolonged period of time should be discouraged.
Funding: No funding sources

Conflict of interest: None declared

Ethical approval: The study was approved by the Institutional Ethics Committee

\section{REFERENCES}

1. Patel SJ, Oshodi A, Prasad P, Delamora P, Larson E, Zaoutis T, et al. Antibiotic use in neonatal intensive care units and adherence with centers for disease control and prevention 12 step campaign to prevent antimicrobial resistance. The Pediatric infectious disease journal. 2009;28(12):1047-51.

2. Clark RH, Bloom BT, Spitzer AR, Gerstmann DR. Reported medication use in the neonatal intensive care unit: data from a large national data set. Pediatrics. 2006;117(6):1979-87.

3. Warrier I, Du W, Natarajan G, Salari V, Aranda J. Patterns of drug utilization in a neonatal intensive care unit. The Journal of Clinical Pharmacology. 2006;46(4):449-55.

4. Straand J, Rokstad K, Heggedal U. Drug prescribing for children in general practice. A report from the møre and romsdal prescription study. Acta paediatrica. 1998;87(2):218-24.

5. Neubert A, Planner C, Cranswick N. The new European regulation on pediatric medicines. Pediatric Drugs. 2008;10(3):147-9.

6. Commission E. Regulation (EC) No. 1901/2006 of the European parliament and of the council on medicinal products for paediatric use. European Commission, Brussels, 2006. Available at http://ec.europa.eu/health/files/eudralex/vol1/reg_2006_1901/reg_2006_1901_en.pdf.

7. Senate and house of representatives of the United States of America Pediatric Research Equity Act, 2003. Available at http://www.fda.gov/downloads/Drugs/DevelopmentA pprovalProcess/DevelopmentResources/UCM077853 .pdf.

8. Bizzarro MJ, Gallagher PG. Antibiotic-resistant organisms in the neonatal intensive care unit. Semin Perinatol. 2007;31(1):26-32.

9. Cotten CM, Taylor S, Stoll B, Goldberg RN, Hansen NI, Sánchez PJ, et al. Prolonged duration of initial empirical antibiotic treatment is associated with increased rates of necrotizing enterocolitis and death for extremely low birth weight infants. Pediatrics. 2009;123(1):58-66.

10. Liem TY, Krediet TG, Fleer A, Egberts TC, Rademaker CM. Variation in antibiotic use in neonatal intensive care units in the Netherlands. Journal of Antimicrobial Chemotherapy. 2010;65(6):1270-5.

11. Dell'Aera M, Gasbarro AR, Padovano M, Laforgia $\mathrm{N}$, Capodiferro D, Solarino B, et al. Unlicensed and off-label use of medicines at a neonatology clinic in Italy. Pharmacy world and science. 2007;29(4):3617. 
12. Cotten CM, McDonald S, Stoll B, Goldberg RN, Poole K, Benjamin DK. The association of thirdgeneration cephalosporin use and invasive candidiasis in extremely low birth-weight infants. Pediatrics. 2006;118(2):717-22.

13. Manzoni P, Farina D, Leonessa M, d'Oulx EA, Galletto P, Mostert $M$, et al. Risk factors for progression to invasive fungal infection in preterm neonates with fungal colonization. Pediatrics. 2006;118(6):2359-64.

14. Downie L, Armiento R, Subhi R, Kelly J, Clifford V, Duke T. Community-acquired neonatal and infant sepsis in developing countries: efficacy of WHO's currently recommended antibiotics-systematic review and meta-analysis. Archives of disease in childhood. 2013;98(2):146-54.

15. Muller-Pebody B, Johnson A, Heath P, Gilbert R, Henderson K, Sharland M. Empirical treatment of neonatal sepsis: are the current guidelines adequate? Archives of Disease in Childhood-Fetal and Neonatal Edition. 2011;96(1):F4-F8.

16. Amikacin. Neonatal formulary 6 - drug use in pregnancy and the first year of life: Wiley Blackwell; 2011:40. Available

at https://pharmafed.files.wordpress.com/2013/04/neona tal-formulary-drug-use-in-pregnancy-and-the-firstyear-of-life.pdf.

17. Engler D, Schellack N, Naude A, Gous A. Use of amikacin in neonates and related ototoxicity: neonatology; 2013. Available at http://reference.sabinet.co.za/document/EJC131751.

18. Vancomycin. Neonatal formulary 6 - drug use in pregnancy and the first year of life: Wiley Blackwell, BMJ Books; 2011:264.

19. Meropenem. Neonatal formulary 6 - drug use in pregnancy and the first year of life: Wiley Blackwell; 2011:161.

20. Linezolid. Neonatal formulary 6 - drug use in pregnancy and the first year of life: Wiley Blackwell; 2011:155.

21. Alcon Laboratories. Tobramycin - summary of product characteristics. Frimley business park, frimley, Camberley, GU16 7SR, UK: EMC; 2012. Available http://www.medicines.org.uk/emc/medicine/21263.

22. Drugs com. Gatifloxacin ophthalmic solution. Wolters kluwer health, 2009. Available at http://www.drugs.com/ppa/gatifloxacin.html.

23. Sanofi. Ofloxacin IV infusion- summary of product characteristics. 1 Onslow Street, Guildford, Surrey, GU1 4YS, UK EMC; 2011. Available at http://www.medicines.org.uk/emc/medicine/8882.

24. Neonatal formulary 6 - drug use in pregnancy and the first year of life: Wiley Blackwell, BMJ Books; 2011. Available http://as.wiley.com/WileyCDA/WileyTitle/productC d-1118819594.html.

Cite this article as: Shinde AR, Bairagi JM, Khanwelkar CC, Shinde RV, Mohite RV. Pattern of antibiotic use in neonatal intensive care unit in tertiary care hospital in Southern India. Int J Basic Clin Pharmacol 2016;5:1563-8. 